\title{
PRAGMATISMO JUDICIAL E IGUALDADE
}

\author{
Leandro Martins Zanitelli*
}

\section{Introdução}

Nas últimas décadas, tem aumentado o interesse pela economia como ciência apta a auxiliar no aclaramento e solução de problemas jurídicos. A principal manifestação desse interesse é, sem dúvida, o que se conhece como análise econômica do direito ou "direito e economia" (law \& economics).

A análise econômica do direito se ocupa com a relação entre normas jurídicas e eficiência, entendida esta como máximo bem-estar (ou, em alguns casos, riqueza) social ${ }^{1}$. Trata ela, assim, de estabelecer quais regras levam a uma situação de eficiência (máximo bem-estar ou riqueza), considerando-se, para tanto, a influência das normas jurídicas sobre os indivíduos ou, em outras palavras, o incentivo resultante dessas normas. Assim, por exemplo, uma lei $L 1$ acerca da responsabilidade civil dos fabricantes de automóveis pode se mostrar preferível, no que respeita à eficiência, a uma outra lei, L2, porque, ao contrário desta, induz os fabricantes a tomar cuidados de baixo custo capazes de prevenir acidentes de potencial gravidade.

No que se refere às decisões judiciais, a análise econômica pode recomendar algo um tanto distinto da prática usual, baseada na Constituição, nas leis em geral e nos precedentes. Ela sugere que os juízes se comportem de modo pragmático (ou conseqüencialista), preferindo, dentre as várias soluções possíveis, a que acarretará maior bem-estar (ou riqueza). O que importa considerar, pois, são os efeitos advindos de cada uma das soluções cogitadas ${ }^{2}$.

Duas razões podem levar à conclusão de que os resultados de uma prática judicial pragmática que persiga a eficiência não seriam tão diferentes dos observados atualmente, não tanto, ao menos, quanto talvez se imagine à primeira vista. A primeira delas é a de que a

\footnotetext{
* Professor de Metodologia do Direito na Faculdade de Direito do Centro Universitário Ritter dos Reis (UniRitter); Doutor em Direito pela Universidade Federal do Rio Grande do Sul (UFRGS). O autor agradece ao UniRitter pela bolsa concedida para pesquisa docente. E-mail: leandroz@orion.ufrgs.br.

1 COOTER; ULEN, 2004

2 O pragmatismo judicial só não será defendido pela análise econômica caso se conclua (por exemplo, devido ao despreparo dos juízes) que sua observância é propensa a trazer mais dano do que benefícios.
} 
obediência à lei e aos precedentes consista, muitas vezes, na solução eficiente, tanto em virtude do conteúdo das normas legais e decisões judiciais anteriores (isto é, porque essas normas e decisões são, por seu conteúdo mesmo, as que redundam em maior bem-estar), como pela segurança jurídica que se obtém ao segui-las (considerando-se, em tal caso, a importância da segurança jurídica para o bem-estar). Assim, é possível que um juiz pragmático disposto a lograr o máximo bem-estar social constate, com freqüência, que o melhor a fazer é respeitar a lei.

A segunda razão é a de muitos juízes já atuarem pragmaticamente, procurando decidir de modo a proporcionar maior bem-estar, embora, geralmente, não o admitam. A hipótese é a de que os juízes, sobretudo nos casos chamados “difíceis", para os quais a lei não dá uma resposta clara, decidam levando em conta única ou primordialmente os efeitos das diversas soluções possíveis sobre o bem-estar social, ainda que, por algum motivo (por exemplo, a previsível oposição ao que se encararia como mais um indício da "politização" do poder judiciário), não o confessem em suas sentenças.

É lícito supor, não obstante, que uma prática judicial pragmática dedicada à promoção do bem-estar social conduziria a mudanças significativas. Nos E.U.A., país em que mais se desenvolveu até agora, a análise econômica do direito leva, constantemente, a propor alterações no direito vigente. Não é absurdo imaginar que o benefício trazido por essas alterações superaria, em muitas ocasiões, o dano à segurança jurídica que elas provocariam, especialmente se realizadas pela via judicial. Por fim, argumentos conseqüencialistas talvez até possam ser apontados como determinantes para algumas das decisões proferidas por juízes hoje em dia, mas não para todas e, dificilmente, para a maioria delas.

Este artigo trata de um dos possíveis óbices à análise econômica e ao pragmatismo judicial nela inspirado, a igualdade. Atente-se para o seguinte caso: $X$ foi a um shopping center e, enquanto fazia compras, teve seu automóvel, que se encontrava na área de estacionamento do shopping, furtado. $X$ pleiteia agora uma indenização. O juiz encarregado do caso, $Y$, é pragmático, e chega à conclusão de que o melhor para a sociedade é rejeitar o pedido de $X$, eximindo o shopping de qualquer responsabilidade pelo furto do veículo (essa solução satisfaria à maioria dos freqüentadores do shopping, que não usa carro para ir às compras e não teria de suportar a alta de preços devida ao pagamento das indenizações). $Y$ sabe que, nos últimos anos, consumidores brasileiros em situação similar à de $X$ têm 
alcançado sucesso em suas ações de reparação de danos ${ }^{3}$, e que, portanto, a sentença de improcedência, sobretudo se não reformada nas instâncias superiores, criará incerteza a respeito da matéria. Ele crê, apesar disso, que os argumentos para a absolvição do shopping são muito fortes e conseguirão, depois de algum tempo, convencer os demais juízes. Por fim, $Y$ avalia que a perda de bem-estar proveniente do abalo temporário à segurança jurídica será compensada, com vantagem, pelo ganho a ser obtido com a nova regra.

Admitindo-se que $Y$ esteja correto quanto aos efeitos de sua decisão sobre o bemestar, poder-se-ia, não obstante, censurá-lo por dispensar a $X$ um tratamento diverso daquele a que foram submetidos, em época recente, inúmeros outros consumidores vítimas de furto de veículo em área de estacionamento comercial. Ao conseqüencialismo se opõe, em tal caso, a igualdade.

Alguns autores ${ }^{4}$ têm posto em dúvida o valor da igualdade (no sentido do exemplo oferecido) como limite ao pragmatismo judicial. Esses autores dão a entender que, se o pragmatismo não for de aceitar, há de ser por alguma razão (como, por exemplo, o excessivo poder que com ele se atribui aos juízes) que não a da igualdade.

O propósito do presente estudo consiste em examinar as objeções à igualdade como obstáculo a uma prática judicial pragmática destinada à elevação do bem-estar ${ }^{5}$. Na primeira parte, depois de uma descrição mais minuciosa do princípio da igualdade em questão, expõem-se os ataques realizados contra ele por Alexander e Peters. $\mathrm{Na}$ segunda parte, esses ataques são refutados. A conclusão é a de que a igualdade há de ser levada em conta nas decisões judiciais, podendo, eventualmente, sobrepôr-se à busca de conseqüências tidas como desejáveis.

\section{0 princípio da igualdade e as objeções}

\subsection{O princípio da igualdade}

Na versão que interessa aqui, o princípio da igualdade é aplicável sempre que a situação de ao menos dois sujeitos for comparável e a um deles tiver sido dispensado certo tratamento $t$. Segundo esse princípio, o tratamento dado a um dos sujeitos envolvidos é uma razão para que o outro seja tratado da mesma forma.

\footnotetext{
${ }^{3}$ V. a súmula n. ${ }^{\circ} 130$ do Superior Tribunal de Justiça.

${ }^{4}$ V. Peters (1996; 1997); Alexander (1989).

${ }^{5} \mathrm{~A}$ igualdade pode ser reconhecida como limite a toda forma de pragmatismo judicial, e não, pois, apenas à que possua como fim a eficiência. Como o conseqüencialismo ligado à análise econômica do direito é, hoje em dia, a espécie mais popular de pragmatismo judicial, o ideal de igualdade defendido no texto acaba se opondo, em particular, à busca pela eficiência.
} 
O princípio da igualdade tem especial importância na hipótese em que o tratamento dado ao primeiro dos sujeitos considerados seja injusto. Suponham-se dois sujeitos em mesma situação, $A$ e $B$. O tratamento a que ambos possuem direito é -t. Entretanto, indevidamente, $A$ obtém $t$. O tratamento recebido por $A$ constitui agora uma razão para que $B$ também seja agraciado com $t$, ainda que - $t$ seja o tratamento a que, em outras circunstâncias, faria jus ${ }^{6}$.

O caso aludido no último parágrafo corresponde ao do exemplo do furto de veículo examinado acima. Razões independentes (na hipótese, conseqüencialistas) determinavam que $X$ não fosse indenizado pelo furto de seu automóvel. Como, porém, outros consumidores em situação idêntica à de $X$ foram vitoriosos em ações ajuizadas contra lojistas, a igualdade exige uma sentença favorável a $X$.

Antes de apresentar as objeções ao princípio da igualdade, convém fazer alguns esclarecimentos. Primeiro, observe-se que esse princípio pode ser aplicado de duas maneiras:

[...] a) como princípio "trunfo", que prevalece sobre todos os demais; e b) como princípio propriamente dito (considerando-se o sentido mais em voga, atualmente, na teoria jurídica), do qual decorre uma simples razão, não necessariamente decisiva, para determinada decisão.

É importante esclarecer que as críticas a seguir indicadas se referem às duas formas de aplicação do princípio, e não apenas à primeira ${ }^{7}$. Assim, para rebatê-las, não é preciso demonstrar que a igualdade possui um valor incontrastável (como em "a"), mas, tãosomente, que ela é de algum valor (o que é o caso de "b"). Voltando ao exemplo do furto, o que importa é estabelecer se as decisões judiciais precedentes constituem, de fato, uma razão (decorrente do princípio da igualdade) para que $X$ seja indenizado. Como não é preciso que tal razão prepondere em todos os casos, é perfeitamente possível admitir que sim e, ao mesmo tempo, sustentar que a ação proposta por $X$ deve ser rechaçada.

\footnotetext{
${ }^{6}$ Se $t$ fosse o tratamento merecido independentemente por $A$ e $B$, o fato de $A$ lograr $t$ não cria dúvida alguma sobre o tratamento a que $B$ tem direito $(t)$. Isso, contudo, não significa que, em tal hipótese, o princípio da igualdade seja inócuo. $O$ tratamento (justo) recebido por $A$ torna o eventual erro de dar $-t$ a $B$ moralmente mais condenável.

7 Alexander (1989, p. 11-12) confere valor à igualdade apenas em caso de dúvida ou, no que se refere a decisões de épocas diferentes, quando se tratar de decisões discricionárias ou sobre bens "competitivos" (um bem é competitivo quando a quantidade a ser entregue a cada um depende do total disponível e do número de indivíduos que a isso fazem jus; quando um bem é competitivo, dar a um indivíduo mais do que o devido implica deixar a outro uma porção insuficiente). Se a decisão é discricionária, não se trata nunca de repetir um erro cometido no passado, já que a decisão mais antiga não pode ser considerada incorreta. Quanto aos bens competitivos, a igualdade pode ser requerida pelo princípio que governa a distribuição desses bens, que não se confunde com o princípio de igual tratamento aqui examinado.
} 
Outra distinção relevante é a que respeita às justificativas para aplicação do princípio da igualdade. Essas justificativas podem conferir à igualdade um valor em si mesma ou apenas como meio para a obtenção de um ou mais fins desejáveis independentemente dela. No caso de $X$, por exemplo, pode-se pretender que a ação seja julgada procedente simplesmente para que não haja diferença de tratamento (isto é, reconhecendo-se à igualdade um valor em si) ou simplesmente para evitar a possível reação inconformada de $X$ (e de outras vítimas de furto às quais se negue reparação) a essa diferença. $\mathrm{Na}$ segunda hipótese, a igualdade não é senão um meio a serviço de fins (como a paz ou o respeito às decisões judiciais), esses, sim, apreciáveis em si mesmos.

$\mathrm{O}$ debate que se tem em vista neste trabalho se refere exclusivamente à igualdade como valor-fim. Essa é uma advertência importante, levando-se em conta se tratar aqui da igualdade como freio ao pragmatismo judicial. É que muitas das justificativas instrumentais para a aplicação do princípio da igualdade estão ligadas (como na segunda das duas hipóteses aventadas no parágrafo anterior) às conseqüências de decisões contrárias a esse princípio. Quando a igualdade é preservada somente com o intuito de prevenir certas conseqüências, passa a fazer parte do cálculo característico do pragmatismo ao invés de se opor a ele. Um juiz empenhado em promover a igualdade de tratamento em nome da tranqüilidade, da segurança jurídica ou da confiabilidade do poder judiciário não deixa de ser, apenas por esse motivo, um juiz pragmático.

\subsubsection{Objeções}

As opiniões dos dois autores examinados nesta seção acerca da igualdade como valor-fim divergem ligeiramente. Enquanto um deles, Peters, não atribui à igualdade qualquer valor em si mesma, o outro, Alexander, mostra-se mais cauteloso ao afirmar que a importância da igualdade, caso haja alguma, é bastante pequena ${ }^{8}$. Além disso, os argumentos de Alexander, ao contrário dos de Peters, referem-se apenas à exigência de igualdade intertemporal (isto é, à exigência de repetir, no presente, o tratamento dispensado a casos similares no passado).

\subsubsection{Peters $^{9}$}

\footnotetext{
$8 \mathrm{~V}$. a nota anterior.

9 Os números de páginas indicados entre parênteses nesta subseção se referem a Peters (1996). Alguns dos argumentos contrários à igualdade são reproduzidos em Peters (1997).
} 
Embora defina o princípio da igualdade (ou, em suas palavras, a igualdade como norma substantiva) exatamente à maneira feita aqui, Peters se ocupa, em especial, com os casos em que esse princípio reivindica dar a alguém um tratamento errôneo (se considerados os demais princípios aplicáveis), aparentemente porque esses seriam os únicos casos em que o mandamento de igualdade surtiria algum efeito ${ }^{10}$.

a) a igualdade é contraditória

Peters alega que obedecer à igualdade geralmente implica, ao mesmo tempo, violá-la ${ }^{11}$. Isso porque, se a ação de $X$ contra o shopping center, for acolhida a fim de que ele não receba um tratamento diverso do concedido a outras vítimas de furto de veículo em áreas de estacionamento comercial, estabelecer-se-á uma diferença entre $X$ e todas as demais pessoas que tiverem sido tratadas de forma justa. Em outras palavras, sempre que, em nome da igualdade, um caso for decidido de maneira incorreta, ter-se-ão tratado desigualmente as partes desse caso e as de outros casos que foram julgados corretamente.

A comparação entre $X$ e outros sujeitos pode ser realizada em termos menos genéricos, restringindo-se, por exemplo, às pessoas que sofreram dano sem ter direito à indenização. Entre essas pessoas, estão algumas indenizadas indevidamente (como as vítimas de furto de veículo em shopping center) e outras cujas ações foram acertadamente negadas. Dar provimento ao pedido de $X$ levá-lo-ia à situação idêntica à das primeiras, mas, em contrapartida, infringiria o princípio da igualdade no que concerne às últimas.

b) a igualdade é arbitrária

A igualdade é arbitrária, pois faz com que o devido a uma pessoa dependa de algo moralmente irrelevante, a saber, a ordem seqüencial dos tratamentos ${ }^{12}$. Imaginem-se dois indivíduos, $Z$ e $X$, ambos vítimas de furto de veículo em shopping center. Se a ação movida por $Z$ for julgada em primeiro lugar e tiver resultado favorável ao seu autor, o princípio da igualdade requer que $X$ também seja indenizado. Caso, ao contrário, $X$ tenha seu pedido apreciado antes, não terá direito (segundo o que se supôs acima) à reparação. Logo, como conseqüência do princípio da igualdade, o tratamento a ser dispensado a $X$ variará de acordo com a ordem (fortuita) de julgamento das ações propostas por ele e $Z$.

\footnotetext{
${ }^{10}$ Peters 1996, p. 2071

${ }^{11}$ Peters. 1996, p. 2068-2069

12 Peters. 1996, p. 2068-2069 
c) a igualdade da lugar à incoerência

Com a igualdade, alega Peters, abre-se mão da coerência ${ }^{13}$. Considere-se um sistema de normas morais $S$ que seja coerente. Quando a esse sistema se acrescenta o princípio da igualdade, $S$ passará, em alguns casos, a exigir que soluções injustas (isto é, contrárias às suas demais normas) prevaleçam a fim de evitar diferença de tratamento ${ }^{14}$. Essas soluções, no entanto, estarão em desarmonia com as que forem dadas para casos aos quais o princípio da igualdade não se aplique, ou em que esse princípio não possua peso suficiente. Logo, a igualdade suprime a coerência de $S$.

d) o que há de errado com leis à moda "tabuleiro de xadrez"?

Em sua defesa da integridade como virtude política, Dworkin faz menção ao que chama de leis à moda "tabuleiro de xadrez"15 (checkerboard statutes) e à repulsa que elas costumam provocar. Pôe-se, então, a pergunta: o que há de errado com essas leis? De acordo com Dworkin, quando uma sociedade se encontra dividida sobre questões de justiça (como, por exemplo, a da proibição ao aborto ou a do regime de responsabilidade a aplicar aos fabricantes de veículos), o mais acertado, considerando-se um ideal de political fairness, seria promulgar leis que refletissem a divergência reinante - leis "tabuleiro de xadrez". Em uma sociedade na qual a metade dos cidadãos sustenta o direito das mulheres a abortar, um exemplo de lei assim seria uma que permitisse o aborto apenas para as mulheres nascidas em anos pares. A oposição aos checkerboard statutes não poderia, portanto, advir de algum sentimento relacionado à injustiça procedimental. Essa oposição tampouco se explicaria por razões de justiça (material), já que, no que concerne aos resultados, as leis tabuleiro seriam sempre preferíveis a pelo menos uma das alternativas, a de tratar a todos injustamente. Para os simpatizantes do direito ao aborto, uma lei que concedesse tal direito à metade das mulheres redundaria em menos injustiça do que outra que negasse o mesmo direito a todas elas.

Para Dworkin, a rejeição às leis tabuleiro de xadrez deriva do reconhecimento, em geral inconsciente, de uma virtude distinta da justiça e da political fairness, que ele designa como integridade $^{16}$. A integridade requer que os cidadãos sejam tratados segundo o mesmo conjunto de princípios (de justiça e fairness), e que esse conjunto seja tão coerente quanto possível.

\footnotetext{
${ }^{13}$ Peters. 1996, p. 2071

14 A não ser, é claro, na improvável hipótese de que não haja erros.

${ }^{15}$ Dworkin. 1986

${ }^{16}$ Dworkin. 1986, p. 183-184 
Embora integridade e igualdade não se confundam (a integridade não se contenta com igual tratamento; também requer tratamento com base em princípios), a primeira impõe, ocasionalmente, a aplicação de princípios errôneos empregados no passado ${ }^{17}$. Referindo-se a um caso de reparação de dano moral, afirma:

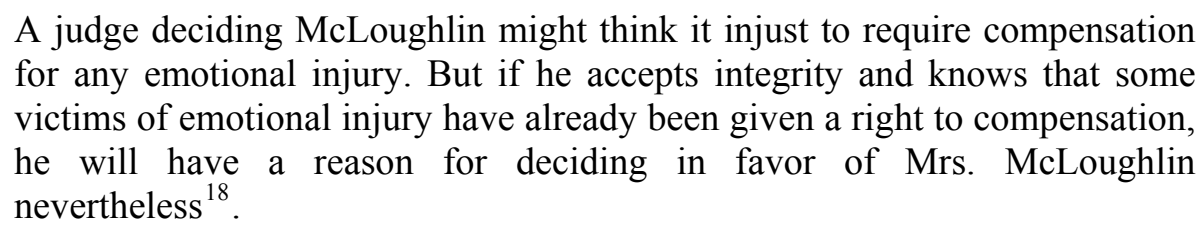

As demandas da integridade coincidem, portanto, em parte, com as da igualdade.

Daí porque, ao argumentar contra a igualdade, Peters precise também se lançar contra a virtude defendida por Dworkin, à medida, ao menos, que ela requeira a repetição de erros cometidos no passado.

Peters discorda de Dworkin por três razões, basicamente. As duas primeiras estão ligadas à reprovação que as leis tabuleiro de xadrez habitualmente suscitam. Segundo, Dworkin erra ao supor que a reação provocada por essas leis deva ser considerada abstratamente, sob uma espécie de "véu de ignorância" que permite contar com a divergência acerca de certas questões e com as duas formas de solução possível para essa divergência (leis à moda "o vencedor leva tudo" ou tabuleiro de xadrez), mas não saber que questões são essas e os princípios que elas envolvem ${ }^{19}$. Além de ser muito difícil determinar como alguém reagiria à idéia de checkerboard statutes em tais circunstâncias, a estratégia usada por Dworkin para demonstrar que a integridade é uma virtude imperceptivelmente aceita ignora que a repulsa a leis assim só se verifica em concreto, podendo ter como causa a crença (não autorizada sob as condições do véu de ignorância, mas perfeitamente possível para indivíduos histórica e geograficamente situados) de que um processo político com a regra "o vencedor leva tudo" está fadado a produzir mais justiça do que injustiça.

Outro motivo para que o mal-estar a que dão lugar as leis tabuleiro não se atribua, como imagina Dworkin, à distinta virtude da integridade, é o de que essas leis tratam a todos injustamente $^{20}$. Peters embasa essa afirmação em um conceito de justiça distinto do de

17 No âmbito judicial, a integridade pede aos juízes que decidam casos com base nos princípios que melhor justificam decisões (leis, precedentes, etc.) passadas. Como essas decisões nem sempre são corretas, os princípios a adotar se mostrarão, algumas vezes, inadequados.

${ }^{18}$ DWORKIN. 1986, p. 183-184

${ }^{19}$ Peters. 1996, p. 2.093-2.095.

20 Peters faz, ao todo, menção a três espécies de solução tabuleiro: ineqüânime, eqüânime e falso tabuleiro (1996, p. 2.095-2.102). No texto, trata-se apenas da primeira, por ser a única que leva sujeitos em situação similar a receber tratamento distinto. 
Dworkin, para quem a justiça diz respeito aos resultados do processo político, isto é, à distribuição de bens e encargos advinda desse processo. De acordo com, a justiça tem a ver com os resultados, mas também com as razões que os determinam ${ }^{21}$. Desta forma, uma lei que confere direito ao aborto apenas às mulheres nascidas em anos pares pode ser tida como justa ou injusta não só por seus efeitos jurídicos (algumas mulheres, aproximadamente a metade, terão direito a abortar, as demais não), como pela razão ou critério (a data de nascimento) usado para atribuir o direito em questão.

Ao contrário do que sugere Dworkin, as leis tabuleiro de xadrez não redundam obrigatoriamente em menos injustiça do que uma das alternativas a prevalecer na hipótese de se obedecer à regra "o vencedor leva tudo". Isso porque, ainda que propiciem resultados parcialmente corretos, as leis tabuleiro o fazem segundo critérios errôneos. Assim, praticam injustiça em todos os casos. No exemplo do parágrafo anterior, a lei sobre aborto é injusta não apenas por recusar o direito à interrupção da gravidez para algumas mulheres (supondo-se que elas possuam, moralmente, esse direito) ou por outorgá-lo às demais (supondo-se que o aborto seja injusto), mas porque concede o direito a abortar segundo um critério moralmente irrelevante. Logo, inclusive as mulheres em relação às quais a lei proporciona um resultado justo são, em certo sentido, tratadas injustamente, por lhes ser reconhecido (ou negado) um direito com base em uma razão espúria. Dworkin se equivoca, pois, ao dizer que a rejeição às leis tabuleiro não pode ser explicada pela contrariedade dessas leis à justiça. Os checkerboard statutes são profundamente injustos, e é essa, e não a ofensa à integridade, a causa pela qual se mostram pouco atraentes.

O terceiro argumento de Peters contra a integridade se refere à prática judicial ${ }^{22}$. Ainda que a integridade possuísse algum valor (o que, para ele, não é o caso), sua aplicação se cingiria ao âmbito legislativo. É que os legisladores, diferentemente dos juízes, podem atender à integridade e à justiça ao mesmo tempo. Com poderes muito menos restritos, os legisladores podem aprovar de uma só vez leis reformadoras de uma inteira área do direito, tornando a última, ao mesmo tempo, justa e consistente. Os juízes, por sua vez, só podem enfrentar uma questão (ou, no máximo, algumas) de cada vez e, em conseqüência, são forçados a optar, freqüentemente, entre a integridade (que os levaria a decidir com base nos mesmos princípios, eventualmente errôneos, usados por outros juízes no passado) e a justiça. Logo, se a falta de integridade é censurável em algum nível de atividade, este é o dos legisladores, e não o dos

\footnotetext{
${ }^{21}$ Peters. 1996, p. 2.050

22 Peters. 1996. p. 2080-2087 
juízes, que só podem obedecer à integridade (salvo na hipótese em que os princípios seguidos no passado sejam justos) com sacrifício da justiça.

\subsubsection{Alexander}

Em Alexander ${ }^{23}$, encontram-se três argumentos contra a igualdade: um deles é o da contradição, também mencionado por Peters e já apresentado na subseção anterior. Os outros dois se expõem a seguir.

a) dois erros (ou mais) não fazem um acerto

Uma decisão incorreta que submeta alguém ao mesmo tratamento dado a outras pessoas no passado não se torna, por essa razão, menos incorreta. Alexander recorre aqui a exemplos extremos: se membros de determinado grupo foram vítimas de escravidão ou genocídio, dispensar a outros integrantes do mesmo grupo tratamento idêntico será tão perverso quanto da primeira vez. "Neither two nor two million wrongs can make a right, however much they equalize situations. Nor is the two millionth wrong somehow less wrong the first." (id.)

b) a igualdade tem mais apelo quando o erro é mais grave

A igualdade possui a incômoda característica de ganhar peso nos casos em que o erro a repetir é mais grave. Quanto maior o erro praticado no passado, mais notável a diferença de tratamento que se estabelecerá na hipótese de o caso atual ser solucionado de forma justa. Se $Z$ foi, tempos atrás, tratado com grande injustiça, e $X$, hoje em situação similar, recebe tratamento diverso, a diferença entre $Z$ e $X$ será marcante. É em ocasiões assim que a igualdade tem mais apelo, mas é nelas, também, que o empenho em assegurá-la contradiz com mais severidade a justiça, o que constitui um inconveniente bastante sério.

\section{A igual importância: resposta às objeções}

A segunda e última parte do texto responde aos argumentos da primeira, defendendo o valor da igualdade como limite a uma prática judicial pragmática. Afirmar-se-á, independentemente das conseqüências eventualmente benéficas (relacionadas, por exemplo, ao aumento da segurança jurídica) de decisões judiciais em que se dê às partes tratamento

\footnotetext{
${ }^{23}$ Alexander. 1989 
idêntico ao de outros casos semelhantes, que tais decisões atendem a um princípio válido, ainda que sujeito a ser preterido, em certas ocasiões, por outros princípios de maior peso.

Tratar igualmente sujeitos em situação similar faz jus à igual importância dos envolvidos. Permita-se usar aqui um exemplo bastante familiar ao autor e, possivelmente, a muitos dos que lerão este artigo. Um professor tem de aplicar um teste a duas turmas de alunos, $A$ e $B$. Como se realizarão em horários distintos, esses testes não podem ser iguais. Imagine-se que, em tais condições, o professor se esforce para preparar exames que ofereçam, tanto quanto possível, o mesmo grau de dificuldade aos estudantes. Esse é, sem dúvida, um comportamento comum em casos assim. A questão é: por que se age desta forma?

Suponha-se que o professor pudesse elaborar dois testes diferentes, um mais difícil do que o outro, sem que isso lhe suscitasse qualquer aborrecimento. Ele sabe que os estudantes não costumam comparar suas provas com as dos colegas ou, o que talvez seja mais plausível, que não estão aptos a avaliar com exatidão o nível de complexidade das perguntas. Assim, não seria de esperar dos alunos submetidos ao teste mais rigoroso algum descontentamento sério, nada, ao menos, que não se conseguisse aplacar com uma explicação qualquer, ainda que evasiva. Considere-se, ainda, que nenhum dos dois exames imaginados seria, em si mesmo, injusto. Ambos estariam de acordo com o regulamento da escola e apresentariam graus de exigência aceitáveis, ainda que díspares.

Nessas circunstâncias, a razão para que o professor insista em aplicar às turmas $A$ e $B$ provas de mesmo nível não é conseqüencialista ${ }^{24}$. Não há, como se disse, nada a temer quanto à reação dos alunos na hipótese de uma das turmas realizar um teste mais complexo. Tampouco se pode explicar o comportamento do professor em termos de justiça não comparativa: ao elaborar provas de mesmo nível, ele não está satisfazendo a um direito que as turmas $A$ e $B$ possuam independentemente uma da outra (um direito, por exemplo, a um exame com perguntas fáceis). A razão, então, para sujeitá-las a igual tratamento - para comparar as questões das duas provas antes de aplicá-las, alterando ou substituindo algumas dessas questões, quando necessário, a fim de que uma das provas não fique mais difícil parece ser, simplesmente, a de que, para o professor, todos os estudantes possuem igual

\footnotetext{
${ }^{24}$ Razões conseqüencialistas podem determinar o grau de exigência, maior ou menor, a empregar nos exames. $\mathrm{O}$ desejo de contar com advogados mais hábeis, por exemplo, talvez leve um professor de direito a confeccionar provas mais difíceis. É claro que, em tais casos, tratar-se-á de avaliar os estudantes segundo um único padrão de rigor - o que se considere apto a produzir as melhores conseqüências. O exemplo do texto, em contrapartida, supõe que nenhum dos distintos níveis de rigor seja mais adequado do que o outro. Deste modo, o professor se empenha em formular provas com o mesmo patamar de dificuldade apenas para evitar diferença de tratamento.
} 
importância ou valor, e que, portanto, nenhum é merecedor de privilégios ou encargos superiores aos dos demais.

Alguns esclarecimentos. Em primeiro lugar, note-se que o princípio da igualdade, bem como o ideal da igual importância que lhe dá fundamento, têm sua aplicação limitada, naturalmente, aos casos que revelem suficiente semelhança. O igual valor atribuído a um grupo de indivíduos só lhe dá um direito a igual tratamento contanto que não haja alguma razão para distingui-los. Imagine-se, por exemplo, que, no primeiro exame do semestre, o professor, involuntariamente, tenha feito um teste mais difícil para a turma A. Ele pode ver nisso uma razão bastante para, na avaliação seguinte, dar a essa turma um teste mais simples. É evidente que surgirão ocasiões de dúvida a esse respeito - isto é, dúvida sobre se dois casos são essencialmente similares ou se há uma razão para diferenciá-los. Esse, contudo, não é um problema que precise ser examinado aqui.

Segundo, a igual importância é um ideal de abrangência variável. Um professor pode agir movido pelo reconhecimento da igual importância de seus estudantes, mas não da dos estudantes em geral, ou nem mesmo dos estudantes de determinada escola. Ele cuidará, assim, para que o nível de rigor das provas aplicadas aos seus alunos seja o mesmo, sem se preocupar, por exemplo, com os exames preparados pelos outros professores ${ }^{25}$. O princípio pode, pois, estender-se aos habitantes de uma região, aos cidadãos de um país ou a todos os seres humanos ${ }^{26}$. Na esfera jurisdicional, a igualdade ganha força à medida que se reconheça a igual importância daqueles sobre os quais recaem os efeitos das decisões judiciais.

Terceiro, o ideal da igual importância é de ação intermitente, o que significa que ele certamente não se manifesta em toda a decisão na qual esteja em jogo. Ainda que confira idêntico valor aos alunos das turmas $A$ e $B$, o professor pode, eventualmente, ter fortes motivos para tratá-los de modo distinto. Por exemplo, depois de corrigir os testes da turma $A$, ele talvez conclua que estavam exageradamente difíceis e resolva aplicar à turma $\mathrm{B}$ uma prova mais fácil, mesmo que esse seja o último exame do semestre e que não haja, assim, como compensar os estudantes da primeira turma posteriormente. Nas circunstâncias

\footnotetext{
${ }^{25}$ Não é necessário, todavia, que o ideal da igual importância se circunscreva aos que estão sujeitos à ação de alguém, como os alunos em relação ao seu professor. Basta pensar na prática, comum em bancas julgadoras, de atribuir nota a um trabalho acadêmico considerando o tratamento dado anteriormente a trabalhos de similar qualidade.

${ }^{26}$ Além de geográficos, os limites do ideal da igual importância podem ser temporais. Desta maneira, por exemplo, encontrar-se-ão ações baseadas no igual valor dos cidadãos de um país em uma certa época, mas não na igualdade entre estes e os que viveram um século antes. Não há, porém, nenhuma razão para pensar que esse ideal apenas dê lugar a decisões de igualdade intratemporal (como a do professor no exemplo do texto), sem exigir, jamais, a repetição de erros do passado.
} 
descritas, pode parecer preferível submeter os alunos da turma $B$ a uma avaliação adequada do que assegurar igual tratamento ${ }^{27}$. A aludida intermitência explica por que a norma da igualdade é obedecida à moda de um princípio (no sentido usual, hoje em dia, da teoria do direito), ou seja, uma norma não aplicável à maneira "tudo-ou-nada", que constitui uma simples razão, nem sempre prevalente, para uma decisão ${ }^{28}$.

As objeções ao princípio da igualdade são examinadas a seguir. Na primeira seção, enfrentam-se as objeções que se referem ao conflito entre igualdade e justiça. A segunda seção é dedicada aos argumentos de Peters contra a integridade. Por fim, trata-se da acusação de que a igualdade, à medida que exija dispensar igual tratamento em épocas diferentes, revela-se arbitrária.

\section{Igualdade e justiça}

Boa parte das objeções reproduzidas na primeira parte se relaciona, de um modo ou de outro, à oposição entre igualdade e justiça. Algumas o fazem mais cruamente: a igualdade contraria a justiça, afirma Peters; nem dois, nem dois milhões de erros redundam em um acerto, lembra Alexander.

Igualdade e justiça são, é inegável, virtudes potencialmente antagônicas. De acordo com a igualdade, casos em essência similares devem ser tratados da mesma maneira. Assim, se $Z$ obteve uma vantagem qualquer, ainda que indevida, no passado, a igualdade pedirá que $X$, cuja situação é semelhante, seja beneficiado na mesma medida.

Deve-se reconhecer, entretanto, que esse antagonismo, tão simples de perceber em teoria, não é observável com a mesma facilidade na prática. Juízos morais (independentemente do status que se lhes queira dar) têm, para a maioria das pessoas, plausibilidade variável. Enquanto algumas opiniões se consideram irrefutáveis - acredita-se, por exemplo, que o genocídio e a escravidão são perversos, que as liberdades de expressão e credo devem ser asseguradas -, outras não se mostram tão firmes. É comum dizer algo como "as quotas para estudantes negros em universidades não me parecem más, embora confesse ainda não ter pensado o bastante no tema" ou "à primeira vista, sou contra a adoção por homossexuais, mas admito mudar de idéia se você me apresentar um bom argumento". A

\footnotetext{
${ }^{27} \mathrm{O}$ que não significa que a igualdade só tenha alguma força quando a decisão a tomar seja discricionária. Em sua versão original, o intuito do exemplo foi mostrar como o esforço para elaborar provas iguais pode ser explicável unicamente pela crença no igual valor dos alunos. Sobre os casos de oposição entre a igualdade e a justiça, tratar-se-á em seguida (v. a subseção 2.1.).

${ }^{28}$ V. Dworkin (1978) e Alexy (1996).
} 
incerteza acerca de questões morais ${ }^{29}$ torna difícil verificar quando há, de fato, divergência entre justiça e igualdade. Se houver dúvida sobre o que a justiça requer nas hipóteses de furto de veículo em shopping center, também não se poderá afirmar com segurança se a igualdade se opõe, em tal caso, à justiça.

A incerteza aludida no parágrafo anterior não é importante só para um possível inventário dos casos em que as demandas da justiça e da igualdade colidem. Ela também deve ser levada em conta quando se trata de estimar o peso da igualdade. Quanto menos firme for a conclusão relativa à superioridade, no que respeita à justiça, de uma solução sobre a outra, maior a razão para escolher, dentre os desfechos possíveis, o que satisfaça ao princípio do igual tratamento ${ }^{30}$.

É preciso ainda ter em vista que, entre os casos de conflito entre justiça e igualdade, nem todos são daqueles em que, para atender à exigência de igual tratamento, um ato profundamente injusto tem de ser praticado, como, por exemplo, o de sujeitar os negros do século XXI à mesma escravidão de que foram vítimas seus ancestrais. Muitas vezes, a decisão a tomar é entre aplicar um princípio $P 1$, usado reiteradamente no passado, e um outro princípio, $P 2$, que, embora se repute superior ao primeiro, não o é em grande medida, havendo, em favor de $P 1$, argumentos quase tão persuasivos quanto os que apóiam o princípio rival. Em tais ocasiões, não parece absurdo preferir $P 1^{31}$. A quem se opusesse, lembrando que, afinal, $P 2$ é o princípio a ser seguido por razões de justiça, poder-se-ia responder da seguinte forma: “A solução mais justa seria, de fato, a ditada pelo princípio P2. Não foi fácil, todavia, chegar a essa conclusão, já que há um outro princípio de peso, $P 1$, impondo solução diversa. Embora esteja convencido de que P2 é melhor do que P1 (ao menos nas circunstâncias do caso), percebo que a distância entre eles, moralmente falando, é pequena. A solução conforme ao princípio $P 1$, além de defensável em si mesma (não penso aqui na segurança jurídica), faz jus à igual importância que têm, para os órgãos judiciais, os cidadãos do presente caso e os que estiveram envolvidos anteriormente em casos similares. Opto, portanto, por P1."

\footnotetext{
${ }^{29} \mathrm{~A}$ incerteza a que se faz referência não é uma característica ínsita aos juízos morais (que se poderia atribuir, por exemplo, à sua inverificabilidade). Ela se refere, simplesmente, ao modo, mais ou menos confiante, como encaramos nossas conviçcões sobre a moral. Não está associada, portanto, a nenhuma forma de ceticismo.

${ }^{30}$ É claro que também pode haver dúvida sobre se duas situações são suficientemente semelhantes e, em conseqüência, sobre se o princípio da igualdade é ou não aplicável. No texto, alude-se a casos em que, embora $X$ e $Z$ se encontrem, indiscutivelmente, em situação análoga à luz do princípio $P$, não se está seguro para afirmar que $P$ seja justo.

${ }^{31}$ Simons. 2000, p. 763-764) 
A contrariedade à justiça não é, portanto, o bastante para negar à igualdade qualquer influência, sobretudo nas hipóteses, recém-mencionadas, em que a questão de fundo (a questão de justiça) não tem uma resposta segura ou admite uma ou mais soluções quase tão boas quanto a que a justiça requer.

\section{a) igualdade e contradição}

A fim de responder ao argumento de que a igualdade, ao se confrontar com a justiça, cai em contradição - uma vez que, determinando a repetição de um erro, desiguala as partes do caso em relação a todos os que foram tratados devidamente -, é preciso levar em conta uma característica do ideal da igual importância até aqui não salientada. Além de abrangência variável e ação intermitente, a igualdade de valor ou importância possui uma eficácia limitada quanto à matéria ou à quantidade de atos a que se refere. O igual valor concedido aos estudantes, por exemplo, pode levar um professor a preparar provas de mesmo nível de dificuldade, mas não a considerar o número de horas disponíveis para estudo de cada aluno. Quando condena o shopping center a indenizar $X$ pela perda do automóvel, o juiz $Y$ pode estar convencido de que, para os órgãos jurisdicionais, $X$ é tão importante quanto as outras vítimas de furto de veículo. Isso, contudo, não fará $Y$ elevar a reparação devida a $X$ para lhe propiciar a compra de um carro tão caro e potente quanto o de seu vizinho.

Os motivos para essa redução de eficácia não são, ao contrário do que podem sugerir os exemplos, apenas de ordem institucional. É certo que um professor não está, normalmente, habilitado a avaliar seus alunos de acordo com a quantidade de horas disponíveis para estudo, nem um juiz pode se pronunciar senão sobre aquilo que lhe é solicitado. A restrição de eficácia, no entanto, também se deve a limites cognoscivos. Considere-se o caso do pai que, depois de ter permitido que sua filha fosse a um show com apenas treze anos, percebe que se equivocou e precisa responder a um pedido semelhante do filho caçula, agora com a mesma idade ${ }^{32}$. Admita-se, por hipótese ${ }^{33}$, que ele autorize o outro filho a ir ao show com o intuito de lhe dispensar igual tratamento. Ao fazê-lo, possivelmente não leve em conta a situação do filho mais velho, que, ao invés de música, gosta de surfe e nunca teve licença para freqüentar praias exageradamente perigosas ou inadequadas para a

\footnotetext{
32 O exemplo é inspirado em Alexander (1989, p. 7).

${ }^{33}$ É bem provável que à igualdade de tratamento se sobreponham, em tal caso, razões mais poderosas como, por exemplo, a de preservar a saúde do filho.
} 
sua idade. Em relação ao primogênito, a autorização aos outros dois para ir a shows infringe, aparentemente, a igualdade, embora se deva acrescentar que ele pôde dedicar ao lazer alguns fins-de-semana em que deveria ter estudado, o que nunca aconteceu com seus irmãos.

Para garantir plena igualdade entre os filhos, o pai do caso proposto disporia de duas alternativas: ou tratá-los sempre corretamente ou, verificando ter praticado alguma injustiça, atribuir a cada um deles uma porção equivalente de vantagens ou encargos indevidos. A ambas alternativas se opõe, além da falibilidade, a limitada aptidão do ser humano para o enfrentamento de questões morais. Como não é possível lidar com muitas dessas questões ao mesmo tempo, A um pai não é dado, por exemplo, examinar e rever continuamente todas as decisões concernentes a seus três filhos (sem falar na dificuldade, levantada pela segunda das alternativas, de comparar vantagens ou encargos de diferente natureza).

A igual importância não pode, pois, manifestar-se senão em um âmbito reduzido. Essa constatação convida a reavaliar a acusação de que a igualdade é contraditória. Com tal acusação, são referidas duas formas de igual tratamento: uma, de pequeno alcance, por força da qual um erro verificado no passado pode ter de se repetir, e outra, universal, que assegura a todos, sempre, o tratamento devido. Adverte-se, então, que a realização da primeira "sacrifica" a segunda. Não há, porém, nenhum real sacrifício quando o ideal de que se abre mão é, como no caso em exame, inatingível. O risco de contradição seria um óbice à prática da igualdade somente se ao realizar a primeira, ameaça-se a segunda. Entretanto, essa ameaça, como visto, ergue-se contra um ideal de igualdade utópico, inatingível. O risco de contradição só seria um óbice à prática da igualdade em escala reduzida se esse ideal tivesse de ser levado a sério.

\section{b) igualdade e incoerência}

But equality contradicts justice in every case in which equality can be claimed to have any operation at all (...). As such, a commitment to equality as a substantive norm, if coupled with a commitment to any nonegalitarian notion of justice, is equivalent to a concession that one's moral system can never be fully coherent. There seems good reason to question the validity of such an inherently incoherent morality ${ }^{34}$.

\footnotetext{
${ }^{34}$ Peters. 1996, p. 2.071 
A parte final dessa assertiva, segundo a qual a incoerência é uma boa razão para pôr em causa a validade de um sistema moral, não será examinada aqui ${ }^{35}$. Talvez seja importante observar, em todo o caso, como o compromisso envolvendo igualdade e justiça rejeitado, na passagem acima, pela incoerência que produz - assemelha-se a outros a que dá margem à concepção abrangente de justiça do artigo de Peters ${ }^{36}$. Quando se define justiça como o tratamento baseado na consideração de todos os critérios relevantes, excluídos os que se refiram à igualdade ou à integridade, admite-se que o justo dependa da ação de fatores distintos e potencialmente conflitantes, como, por exemplo, a justiça material, a segurança jurídica ou a separação de poderes. Entre esses fatores, alguns, como os dois últimos, assemelham-se à igualdade na medida em que chamam a atenção sobretudo quando se opõem à justiça (em sentido material). A segurança jurídica, bem como os limites a que, por razões institucionais, deva se sujeitar o poder judicial, importam em especial porque, a exemplo da igualdade, podem requerer uma solução diversa da que seria obtida com base apenas em critérios de justiça material. Logo, se a segurança jurídica, a separação de poderes e a justiça material forem simultaneamente admitidas a influir sobre decisões judiciais, ter-se-á como resultado a mesma forma de incoerência que a igualdade é acusada de provocar.

Assim, a detratores da igualdade como Peters restam duas saídas para manter viva a objeção alusiva à incoerência: uma é pregar que juízes não dêem atenção a critérios heterogêneos (recomendando, por exemplo, o uso exclusivo de critérios de justiça material em decisões judiciais); outra é esclarecer porque se deve tolerar a incoerência resultante da aplicação desses critérios, mas não a que decorre do compromisso entre igualdade e justiça.

\section{c) a gravidade do erro cometido no passado}

Segundo Alexander ${ }^{37}$, se não se considera apropriado aplicar o princípio da igualdade para reproduzir erros graves do passado, também é de se descartar esse princípio quando se trata de erros menos sérios, pois é justamente nos primeiros casos que o apelo da igualdade se mostra mais forte.

Para exame desse argumento, é conveniente esclarecer, em primeiro lugar, o que se entende aqui como "erro grave". Sugere que a gravidade do erro seja medida de acordo com a desigualdade dele resultante: "If we do not follow the seriously wrong decision, the present winning party will be much better off than her equally deserving but losing analog in

\footnotetext{
${ }^{35}$ Sobre o valor da coerência, consulte-se Raz (1992).

${ }^{36}$ Peters. 1996, p. 2.050

${ }^{37}$ Alexander. 1989, p. 11 
the earlier case ${ }^{\text {38 }}$. Em outras palavras: quanto mais incorreta a decisão pretérita, maior será a diferença entre as partes dos dois casos (o anterior e o atual) na hipótese de desrespeito ao precedente.

Um dos problemas com essa resposta é que ela obriga a indicar como a desigualdade há de ser medida ${ }^{39}$. Se o erro é tanto mais sério quanto maior a desigualdade que ele ocasionará, resta saber o que torna a desigualdade entre dois sujeitos maior ou menor. De que tamanho será a diferença entre $X$ e as demais vítimas de furto de veículo em shopping center se ao primeiro for recusada a indenização obtida pelas últimas? Como comparar essa diferença, por exemplo, com a que se verifica entre um estudante a quem foi reconhecido, equivocadamente, o direito a freqüentar determinado curso superior e outro que teve negado o mesmo direito ${ }^{40}$ ?

A falha fundamental do argumento, no entanto, é supor que a vinculação ao precedente pretenda obter igualdade segundo algum padrão determinado (que poderia ser o do bem-estar, dos bens primários, dos recursos, das capabilidades etc.), padrão esse que serviria para medir o apelo da igualdade em cada caso. Por exemplo, se o padrão escolhido fosse o do bem-estar, a desobediência ao precedente violaria a igualdade à medida que redundasse em diferença de bem-estar entre o atual demandante e os de julgamentos anteriores.

Ocorre que a escolha desse padrão não pode ser feita ao acaso. Se ela recai sobre o bem-estar ou as capabilidades, é porque são, respectivamente, as diferenças em bem-estar e capabilidades que importam, e não outras. Assim, o padrão indicado interessará também à justiça, e não apenas à igualdade, com a inevitável conseqüência de conduzir esta à posição desconfortável descrita por Alexander. Admitindo-se que igualdade e justiça tenham em vista o mesmo (seja bem-estar, capabilidades ou recursos), é forçoso que a repetição de erros do passado seja tão mais cara à igualdade quanto mais graves (ou contrários à justiça) forem esses erros.

\footnotetext{
${ }^{38}$ Alexander. 1989, p. 11

39 V. Sen (2001, p. 21).

${ }^{40}$ Independentemente do parâmetro usado para aferir a desigualdade, a idéia de gravidade do erro a que se reporta o argumento de Alexander se revela insatisfatória por dizer respeito exclusivamente aos resultados de uma decisão. Suponha-se que o parâmetro escolhido seja o dos bens primários de Rawls. Segundo o que insinua o argumento, um erro seria tão mais perverso quanto maior a quantidade de bens primários impropriamente entregue ou subtraída a alguém. Um ato pode ser tido como injusto, no entanto, não em virtude de seus resultados, mas, simplesmente, porque recusa a uma pessoa algo que lhe é devido. Imagine-se que $X$, após ser derrotado em primeira instância na ação contra o shopping center, tenha sido impedido, em flagrante desrespeito à legislação processual, de interpor recurso. Embora a decisão não o faça dispor de uma quantidade de bens primários inferior à que tem direito (admitindo-se que não haja direito à reparação pelo furto), $X$ foi vítima de injustiça.
} 
A noção de igualdade na qual a sujeição ao precedente se apóia, todavia, não é a subentendida no argumento, isto é, a de igualdade segundo algum padrão determinado. $\mathrm{O}$ princípio de igual tratamento examinado aqui se refere a tratamento com base em um padrão qualquer (ainda que errôneo), não necessariamente o mesmo em todos os casos. Esse princípio contradiz a justiça, é verdade, sempre que requer a repetição de um erro do passado. Como não aspira, porém, à igualdade de algo específico, seu apelo não é determinado à maneira narrada por Alexander. À igualdade importa dispensar a $X$ o tratamento obtido anteriormente por sujeitos em situação similar à dele, o que é diferente de pretender que $X \mathrm{e}$ os demais disponham de mesmo bem-estar ou quantidade de recursos (estas podem ser pretensões válidas, mas nada têm a ver com a idéia de igualdade em discussão).

Desta forma, não há por que atribuir à igualdade um peso maior nos casos em que o erro verificado no passado é mais grave (entendendo-se "erro grave" à maneira enunciada acima). A potencial oposição à justiça sugere (obedecendo-se à máxima da proporcionalidade), ao contrário, que o princípio da igualdade seja preferencialmente aplicado quando o erro praticado no passado for menos sério - em virtude de a solução encontrada ser quase tão boa quanto a recomendada pela justiça - ou houver dúvida sobre o que a justiça requer.

\section{A integridade}

Lembre-se de que o ataque de Peters aos argumentos de Dworkin em favor da integridade como virtude independente da justiça e da political fairness é composto de três partes. Assim, ele alega que: a) Dworkin se equivoca ao propor que o valor da integridade seja reconhecido em abstrato. Ao fazê-lo, desconsidera a hipótese de que a repulsa às leis tabuleiro de xadrez se deva à confiança nos resultados do processo político; b) as leis tabuleiro de xadrez constituem uma solução ao menos tão injusta quanto qualquer outra possível para problemas como o o aborto ou a responsabilidade dos fabricantes de automóveis, e essa, e não a falta de integridade, é a causa pela qual essas leis raramente são adotadas; c) se a integridade tivesse algum valor, este ficaria circunscrito ao âmbito legislativo, no qual se pode atender a ela sem violar a justiça.

a) leis tabuleiro de xadrez e "véu de ignorância"

Ao indagar acerca da razão pela qual leis tabuleiro são rejeitadas antecipadamente, o intuito de Dworkin é determinar por que pessoas com uma firme convicção sobre certa questão de justiça (por exemplo, sobre a imoralidade do aborto) se 
opõem a leis dessa natureza mesmo considerando a hipótese de serem derrotadas no processo político. Para Dworkin, a resposta é de que elas agem desta maneira movidas por um senso de integridade.

É verdade que Dworkin não se empenha em demonstrar que os checkerboard statutes são, de fato, habitualmente rejeitados nas condições recém-descritas. Talvez lhe pareça suficiente observar que essas leis são infreqüentes, ou talvez ele espere que cada leitor faça a verificação necessária, perguntando-se como reagiria à idéia de uma lei tabuleiro de xadrez para regular certa questão que julgue importante. Diferentemente do que pensa Peters , essa verificação pode ser, no mais das vezes, factível, já que o "véu de ignorância" imposto pelo argumento é muito menos espesso do que o imaginado pelo referido autor ${ }^{41}$. $\mathrm{O}$ exame de consciência a realizar aqui não exige desconhecimento das questões particulares de justiça que atraem a atenção de cada um, nem do quão intensamente elas o fazem; pede, apenas, que se cogite, sem levar em conta os resultados (já obtidos ou esperados) do processo político, a hipótese de resolver essas questões por meio de leis tabuleiro.

Para contornar o restante da objeção de Peters, de acordo com o qual a rejeição às leis tabuleiro pode ser motivada exclusivamente pela crença em que o processo político, caso obedecida a regra "o vencedor leva tudo", produzirá mais soluções justas do que injustas (ou mais justas do que com que a regra tabuleiro), é o bastante abandonar a posição ex ante adotada por Dworkin por uma na qual os resultados do processo político já sejam conhecidos. Pode-se então perguntar aos vencidos se aceitariam substituir as leis em vigor por checkerboard statutes que refletissem adequadamente o peso de cada opinião sobrepujada. Se, ao menos em algumas ocasiões, a resposta for negativa (o que é plausível ${ }^{42}$ ), a hipótese levantada por Peters deve ser abandonada.

b) as leis tabuleiro de xadrez são só injustas?

\footnotetext{
${ }^{41}$ Peters. 1996, p. 2.093

${ }^{42}$ É claro que a resposta será “sim” em muitos casos. Defensores fervorosos do direito à vida desde a concepção, por exemplo, possivelmente aceitarão substituir uma lei que confira o direito ao aborto a todas as mulheres por outra à moda tabuleiro de xadrez, considerando melhor salvar algumas vidas a nenhuma. À medida, contudo, que uma questão moral pareça menos crucial, contudo, aumenta a chance de uma solução tabuleiro ser recusada pelos derrotados. Se alguém entende indevida a reparação às vítimas de furto de automóvel em shopping center, mas não crê haver grande diferença entre esta e a solução oposta, pode preferir uma lei que conceda direito à indenização a todos os proprietários de veículos à outra que o faça apenas para os nascidos em anos ímpares.
} 
Outra alegação de Peters é a de que as leis tabuleiro de xadrez são injustas ${ }^{43}$, tanto por seus resultados (em parte, ao menos), como pelas razões em que se baseiam. Esta, e não o desrespeito à integridade, seria a causa de sua impopularidade.

A concepção abrangente de justiça usada por Peters tem um papel crucial nessa parte da argumentação, pois permite concluir que as leis tabuleiro são ao menos tão ruins, em termos de justiça, quanto qualquer solução segundo a regra "o vencedor leva tudo": elas são certamente piores do que uma das soluções da última espécie (a solução correta) e tão ruins quanto a solução oposta.

A resposta a essa objeção também pode ser obtida a partir de uma comparação (mas, não, como faz Peters, da comparação entre uma lei tabuleiro e leis ao feitio "o vencedor leva tudo" aprovadas conforme a vontade da maioria). Retome-se, para exemplificar, a questão do aborto, supondo que os representantes da população estejam reunidos para decidir se concedem ou não às mulheres o direito à interrupção da gravidez. Encerrados os debates, passa-se à votação, e o resultado é um surpreendente empate. Não tendo sido instituída regra alguma sobre como proceder em casos assim, cria-se um impasse.

Propõem-se, então, duas soluções. Uma é a do checkerboard statute imaginado por Dworkin. Devido à divisão de opinião, permitir-se-ia o aborto apenas à metade das mulheres (por exemplo, às nascidas em anos pares). Outra solução é o cara-ou-coroa. Lançase a moeda e a parte vencedora leva tudo, isto é, promulga uma lei aplicável a todas as mulheres regulando o aborto à maneira desejada.

Qual solução é preferível? Observe-se, em primeiro lugar, como elas são equivalentes (ao menos ex ante) no que concerne aos seus resultados. A solução tabuleiro de xadrez renderá resultados $50 \%$ corretos (sejam quais forem), enquanto o cara-ou-coroa tem uma chance em duas de levar a resultados $100 \%$, o que é igual a $50 \%(100 \% \text { x } 1 / 2=50 \%)^{44}$.

As duas soluções também não se distinguem no que se refere às razões do tratamento dado às mulheres. Como diz Peters, a lei tabuleiro é arbitrária, já que, fazendo-se passar uma lei assim, as mulheres terão ou não direito a abortar dependendo do ano em que nasceram - um critério inteiramente aleatório. O mesmo, no entanto, vale para a outra solução cogitada, pois o cara-ou-coroa, evidentemente, também determinará o status jurídico das mulheres quanto ao aborto de modo aleatório.

\footnotetext{
${ }^{43} \mathrm{~V}$., supra, a nota 11.

${ }^{44}$ Ao afirmar a equivalência das soluções, o texto assume a posição de alguém com neutralidade ao risco. Notese que, na hipótese de aversão ao risco, a solução tabuleiro se revelaria mais atraente do que o cara-ou-coroa.
} 
Parece, pois, que as soluções examinadas são igualmente boas (ou igualmente más) em termos de justiça, quer se considere, em relação a esta, apenas os resultados, como faz Dworkin, quer também se tenham em conta as razões, como defende Peters. A situação é outra, porém, no que respeita à justiça procedimental (ou political fairness). Se os representantes dos cidadãos divergem quanto ao aborto, uma lei que reflita essa divergência é superior, em termos de fairness, a outra que não o faça. A justiça procedimental favorece, portanto, a solução tabuleiro.

Deduz-se daí que, nas condições descritas, a opção pelo cara-ou-coroa tem de manifestar o apreço por uma virtude diferente da justiça e da political fairness. Essa virtude pode ser denominada de integridade ou, simplesmente, igualdade. A decisão de lançar a moeda (ignorando-se eventuais razões conseqüencialistas) justificar-se-ia da seguinte maneira:

Infelizmente, não foi possível chegar a nenhum acordo ou compromisso sobre o problema do aborto. Não obstante, nós, parlamentares, estamos convictos de que, em que pese a diferença de opiniões, a solução para esse problema, qualquer que seja, deve ser a mesma para todas as mulheres. Essa é, nas atuais circunstâncias, a forma como podemos expressar o igual valor que possuem, para nós, as pessoas aqui representadas.

c) a integridade e os juízes

Por fim, Peters acredita que o valor da integridade estaria, quando muito, limitado ao âmbito legislativo, uma vez que os juízes atuam de forma fragmentada, não estando em condições de atender ao mesmo tempo à justiça e à coerência. Os órgãos judiciais deveriam, assim, preocupar-se exclusivamente com a justiça.

No início desta parte, argumentou-se que a potencial contrariedade à justiça não impede de reconhecer à igualdade algum valor. Não é necessário retornar aqui a esse ponto.

A diferença observada por Peters entre as atividades legislativa e judicial se presta, curiosamente, a salientar a importância da integridade para a segunda. Afinal, se os juízes, ao contrário dos legisladores, não estão aptos a alterar uma vasta área do direito por meio de uma única decisão, conclui-se que a atividade dos órgãos judiciais constitui, em comparação com a dos legislativos, uma ameaça mais séria à igualdade. Esse é um motivo para que os juízes dêem mais, e não menos, atenção à igualdade em suas decisões.

As dificuldades institucionais enfrentadas pelo poder judiciário (relacionadas ao grande número de juízes, às repartições de competências, ao alcance limitado das decisões 
etc.) para lograr coerência dão, portanto, à medida que se preze a igualdade, uma razão em favor da obediência à lei e aos precedentes (sobretudo pelos juízes das instâncias inferiores) como meio de evitar diferenças de tratamento.

\section{Igualdade e arbitrariedade}

A alegação de que o princípio da igualdade leva o tratamento devido a $X$ se determinar segundo uma ordem moralmente irrelevante de eventos (a ordem em que são decididos o caso de $X$ e o de $Z$, que está em situação similar à daquele) incorre no erro de atribuir importância moral apenas àquilo que respeita à justiça (tal como definida por Peters), e não à igualdade. Tem-se aí, pois, uma petição de princípio.

De fato, a ordem de julgamento das ações propostas por $X$ e $Z$ só é destituída de importância se o padrão moral adotado for o da justiça no sentido não comparativo (natural para um adversário da igualdade) do artigo de Peters. É claro que, de acordo com esse padrão, o tratamento a que $X$ faz jus é independente do que sucedeu (ou sucederá) a $Z$. Para um padrão igualitário, no entanto, o fato de $Z$ ter obtido uma indenização em circunstâncias semelhantes às de $X$ é, sim, relevante, já que pode conduzir à conclusão de que o último deve ser indenizado (contrariamente ao que prescreve a justiça). Assim, ao tratar a seqüência de tratamentos como algo moralmente desprezível, o argumento pressupõe o desvalor da igualdade ao invés de demonstrá-lo.

Além disso, da constatação de que o tratamento a ser dispensado a alguém com base em certo princípio depende de acontecimentos aleatórios não se pode tirar a conclusão de que o próprio princípio em causa seja moralmente perverso. A legislação do seguro social, por exemplo, destina-se, em boa medida, a compensar perdas de bem-estar decorrente de eventos (morte, doenças, acidentes, etc.) independentes da vontade de quem quer seja. Isso não basta, evidentemente, para afirmar que o princípio no qual essa legislação se baseia seja iníquo.

\section{Conclusão}

O exame das objeções relacionadas à justiça e, por último, da acusação de arbitrariedade revela que os ataques de Peters e Alexander à igualdade são insuficientes. A discussão sobre as leis tabuleiro de xadrez indica, por sua vez, que Dworkin talvez esteja certo ao atribuir a rejeição habitual a essas leis ao reconhecimento (tácito, geralmente) do valor da integridade. Segundo o que foi defendido acima, decisões conformes à igualdade ou 
integridade têm como fundamento a igual importância dos indivíduos sujeitos a essas mesmas decisões.

Se a igualdade é um ideal a observar, então o pragmatismo judicial precisa - em uma medida que não se procurou determinar aqui - sujeitar-se a certos limites. Independentemente de considerações de outra natureza (referentes, por exemplo, à subordinação dos juízes à lei), a atenção às conseqüências deve, portanto, ocasionalmente, dar lugar à prática da igualdade.

Artigo recebido em fevereiro de 2007

Aceito para publicação em abril de 2007

\section{Referências}

ALEXANDER, Larry. Constrained by precedent. In: Southern California Law Review. 1986 ALEXY, Robert. Theorie der Grundrechte. 3ª ed. Frankfurt: Suhrkamp, 1996.

COOTER, Robert; ULEN, Thomas. Law and economics. 4ª ed. Boston: Addison-Wesley, 2004.

DWORKIN, Ronald. Taking rights seriously. Cambridge: Harvard, 1978.

. Law's Empire. Cambridge: Belknap, 1986.

PETERS, Christopher J. Foolish consistency: on equality, integrity, and justice. In: The Yale Law Journal, Vol. 105, No. 8 (Jun., 1996), pp. 2031-2115. The Yale Law Journal Company. New Haven.

. Equality revisited. In: Harvard Law Review, Vol. 110, No. 6 (Abril, 1997), pp. 1210-1264. The Harvard Law Review Association, Cambridge.

RAZ, Joseph. The relevance of coherence. In: Boston University Law Review. 72(1992) 273.

SEN, Amartya. Desigualdade reexaminada. Rio de Janeiro: Record, 2001.

SIMONS, Kenneth W. The logic of egalitarian normas. In: Boston University Law Review. 80(2000) 693-771. 


\section{Resumo}

$\mathrm{O}$ artigo trata da igualdade como limite ao pragmatismo judicial. Uma vez que a igualdade exige mesmo tratamento para casos similares, um juiz atento à igualdade pode ser levado a seguir a lei ou as decisões judiciais precedentes ainda que uma solução distinta lhe pareça capaz de produzir melhores conseqüências. Recentemente, Peters e Alexander expuseram argumentos contrários à igualdade, pondo em dúvida que haja alguma razão para prezar a igualdade em si mesma, isto é, para prezá-la independentemente dos efeitos porventura benéficos (relacionados, por exemplo, à segurança jurídica) de uma decisão conforme à igualdade. Esses argumentos são rebatidos aqui.

Palavras-chave: Igualdade. Pragmatismo judicial. Integridade. Conseqüencialismo. Análise econômica do direito.

\begin{abstract}
This work questions equality as a limit to judicial pragmatism. Since equality determines that similar cases must be treated alike, a judge who cares for equality may follow a legal norm or precedent even if another solution could render better results. Recently, Peters and Alexander have argued that equality has instrumental value only and should be considered exclusively for pragmatic reasons. Their arguments are refuted here.
\end{abstract}

Keywords: Equality. Judicial pragmatism. Integrity. Consequentialism. Economic analysis of law. 